\title{
RECENT TRENDS OF RESEARCH ACTIVITIES IN BIOMECHANICS (KINESIOLOGY) 1973 1974
}

\section{Akira TSUJINO \\ Osaka Kyoiku University}

I. Trends in Papers Presented at the J.S.P. E. Conventions :

Forty papers in 1973 and sixty papersin 1974 were submitted at the annual J.S.P.E.

Conventions. Those are listed below under appropriate headings.

\begin{tabular}{l|c||l|c}
\hline Movements, Force, Skill, etc. & Number & \multicolumn{1}{|c}{ Sports } & Number \\
\hline Strength & 8 & Track and field athletics & 15 \\
Power & 7 & Swimming & 10 \\
Perceptual-motor skill & 6 & Gymnastics & 4 \\
Bicycle ergometer & 5 & Baseball & 4 \\
Running & 4 & Weight lifting & 4 \\
Walking & 3 & Ski & 4 \\
Posture & 3 & Judo & 3 \\
Throwing & 2 & Soccer & 3 \\
Vertical jump & 2 & Kendo & 2 \\
Jump motion & 2 & Volley ball & 2 \\
Weight distribution & 2 & Tennis & 1 \\
Center of gravity & 1 & Table tennis & 1 \\
Apparatus for measurement & 1 & Handball & 1 \\
\hline \multicolumn{1}{c}{ Total } & 46 & \multicolumn{1}{c}{ Total } \\
\hline
\end{tabular}

II. Trends in the Second National Biomechanics (Kinesiology) Seminar :

The Seminar was held at the University of Tokyo on November 23 and 24, 1974, sponsored by the Special Research Division of Biomechanics (Japanese Biomechanics Society), with participants more than 150 .

There were two lectures ( $\mathrm{K}$. Ishii and $\mathrm{K}$. Takgi), one symposium, twenty papers with special reference to "Skill in physical activities", and one special lecture given by the guest speaker, Professor Shinichi Nomura, University of Tokyo.

The theme has been followed for the past three years.

Through those investigations and discussions, there appeared gradually a general agreement to the effect that more attention should be paid to the role played by the central nervous system in performing sports feats.

Such tendency can be perceived in the top category of following presentation.

(1) Papers presented :

a. Perceptual-Motor Skill

"Attitude of Perceptual-Motor Actions in the Central Nervous Systems" (M. Shino), 
"Regulations in Pedalling Bicycle Ergometer" (S. Ohara), "Skill from Viewpoint of the Force-Velocity Relation in Human Leg Extension" (K. Kawahatsu), "Dexterity in Motor Control:Characteristics of Frequency Response" (A. Nagata), "Mechanism of Silent Periods Preceding the Act in Voluntary Movements" (K. Yabe).

b. Efficiency

"Training Effects of the Work with Bicycle Ergometer" (H. Yamamoto).

c. Sports Skill

"Rowing" (H. Sano), "Skiing Turn" (T. Maejima), "Gymnastics" (N. Yamashita), "Hurdling" (Y. Goto), "Middle and Long Distance Running" (K. Yamaji), "Long Distance Running", (M. Miura), "Clean and Jerk" (K. Ueya), "Speed and Accuracy in Ball Throwing" (S. Toyoshima), "Mechanism of Twisting Motion", (F. Kosa), "Kick Force in Vertical Jump", (H. Nomura), "Relationship Between Motion and Respiration", (Takaaki Asami), "Basic Research on Skill Training", (G. Hirohashi).

d. Motor Skill in Infants

"Swimming", (H. Tokuyama), "Running and Jumping", (M. Miyamaru).

(2) Symposium :

Skill in Physical Activities from the Viewpoint of Biomechanics (Chairman, Toshio Asami).

"Muscular Function", (M. Kumamoto), "System Theory", (K. Kobayashi), "Efficiency", (M. Miyashita). 